\title{
Study on the Reasons for the Mistakes in Air Traffic Control in Civil Aviation and Its Management Countermeasures
}

\author{
Xiaoshuo Zhao
}

Sanya Aviation \& Tourism College, Sanya, Hainan, 572000

\author{
Keywords: Air Traffic Control, Civil Aviation, Management Countermeasures
}

\begin{abstract}
With the economic development in our country, the development of China's fame area has also entered a new stage. The overall level of civil aviation has been correspondingly raised. At the same time, the improvement of people's living standards has also made the demand for civil aviation more and more large, leading to the rapid development of civil aviation and some problems in the development of civil aviation. In the new era of civil aviation development, people pay more and more attention to civil aviation risk issues. Therefore, it is very important to civil aviation air traffic control. This paper studies the cause and risk management of air traffic control in civil aviation, so as to promote the development of civil aviation in China.
\end{abstract}

\section{Introduction}

The rapid development of China's civil aviation to promote China's economic progress, while the corresponding provisions in the civil aviation traffic, are subject to the air traffic management indicators, which can guarantee the quality of control traffic management. Therefore, civil aviation air traffic control errors and risk management can promote the development of civil aviation air traffic and improve the level of civil aviation air traffic control.

\section{Causes and Risk Management of Air Traffic Control in China Civil Aviation}

In the light of the development of the new period, China's civil aviation air traffic management should be optimized and rationally formulated. The main purpose of traffic management is to make air traffic more secure. Therefore, the management should be more scientific and airborne Traffic management content design more, among the management to be combined with the actual situation of management, the ultimate goal of air management differentiation, and then step by step implementation of the management process in the implementation of the production and safety indicators and indicators, as well as measures indicators The combination of ways to make the various indicators to be implemented. Traffic control errors in civil aviation are caused by a variety of reasons. Among the objective factors, air and noise levels can be affected when staff members deal with problems, thus reducing work efficiency and thus affecting the work in the affected situations Personnel prone to errors, resulting in increased insecurity. At the same time in carrying out civil aviation flights in the meteorological conditions will have a significant impact. Subjectively, subjective factors mainly include the fact that the professional knowledge of controllers is not enough, there is no high experience in work, the work done in assigned work is not done enough in time, and the quality of traffic control is affected by many factors. The status of traffic controllers themselves will also affect traffic control as well as a major part of the impact on air traffic control. The main reason for this is the lack of scientific division and insufficient staff training. All of the above will affect traffic control Control has an impact, so there is a problem with the quality of regulation.

\section{Causes of human error in air traffic control}

The main causes of controller errors in air traffic control are generally due to such factors as "people, communication equipment, work environment and safety management". Among the many 
factors such as "man, equipment, environment and management", the most important factor Is "management." Because management factors can directly and indirectly affect and decide the other three factors. Of course, the physical, mental and comprehensive professional qualities of the controller, the interference and defects of the communications equipment used and the control over the working environment are also very important factors. The "management" factor mentioned here is in fact the relationship between people in the SHEL model. According to the timeliness of error can be divided into dominant errors and hidden errors. Dominant errors refer to the conclusion that an error was immediately taken from the result. Errors made by front-line controllers fall into this category. Hidden error is the situation where an error has not been known because the result will not show any immediate adverse effects. Errors related to system workflow design and management fall into this category. Here is reflected in the SHEL model of people and people inside and software and the relationship. In the past we analyzed the accident is limited to dominant errors, security problems often boils down to front-line staff mistakes. In actual fact, in the final analysis is the management and mechanism issues, that is, implicit errors work. Of course, their mistakes are the direct causes of accidents, but these mistakes happen under certain conditions, which in turn depend on the management. In fact, the management, especially the decision-makers, make demands, make regulations, control resources, dominate the way the system operates, and stipulate the working environment and cultural atmosphere of front-line staff. Almost every one of front-line staff can manage to find the reason, which can be reflected in the controller's workload. From the point of view of human physiology, control work is a high-intensity mental work that requires the controller to maintain a nervous state of mind at any time, which can easily lead to brain fatigue. Experiments show that the concentration of the human body continuous work time is 40 min $\sim 1 \mathrm{~h}$, over time there will be a "god" phenomenon, this phenomenon will affect the work, so that operational errors increase. Therefore, the general every $40 \mathrm{~min} \sim 1 \mathrm{~h}$ will be on the post to replace the rest staff to ensure that staff on duty at any time energetic. Therefore, in order to reduce man-made mistakes caused by excessive workload caused by controller fatigue, air traffic control work adopts a 24-hour shift system. However, when controllers work in high workloads and when work loads are low, they are usually out of control. There are many reasons that affect work load and some can not be quantitatively analyzed. Therefore, controllers are overworked Caused by flight insecurity or from time to time happen.

Air traffic control is a very immediate task that requires not only keen insight, improvisation and decisive decision-making of controllers, but also regular training and assessment of them. The air traffic control incident exposed controller skills, unskilled equipment and other issues, to some extent, shows the lack of training and assessment. For example, when jamming of aircraft microphones caused congestion of regulatory frequencies, controllers repeatedly inquired in the microphones about which aircraft's microphones were stuck. This is precisely because of the lack of understanding of the principle of half-duplex land-to-air communication equipment that transceivers can not operate simultaneously and that aircraft pilots can not hear the controller's call. This lack of knowledge will directly lead to the controller to take the wrong solution or miss the timing of the disposal, with serious consequences. Therefore, regular training and assessment of controllers not only enhance their ability to deal with emergencies, but also reduce the controller errors.

\section{Civil Aviation Air Traffic Risk Management Strategy}

To develop a scientific strategy for air traffic risk management, the air traffic control system is very important for air transport and is the basis for safe transport and normal flight. For air traffic, safety is the core of traffic control. Therefore, in formulating Active strategy, we must attach importance to safety management, application of scientific methods in the formulation of strategies to the overall and comprehensive attention to improve the ability of risk management, risk management so that the active strategic level has been strengthened in order to be able to better improve The quality of air traffic management.

To improve the level of risk management should be carried out in many aspects, the administrator of the preventive strategy to manage, at the same time to manage the good habits of 
workers to be cultivated. Civil aviation flight safety and people are closely related, as regulators to correct their own work attitude to develop good working habits, while constantly improving the level of their work, in the control of work to strictly abide by the workflow, but also advanced The idea of management should be applied scientific methods to improve the quality of work.

When carrying out civil aviation air traffic management, the rules and regulations should be scientifically and systematically formulated. The contents of the system should be combined with the actual conditions to effectively improve the management and to apply scientific methods to the coordination of the control groups. More information should be communicated, more attention should be paid to the basic work, and a crisis plan should be set up and improved at the same time. The relevant laws and regulations of civil aviation should be clarified. At the same time, the state should also improve laws and regulations so that Help to improve the level of risk management.

The level of air traffic control in civil aviation is inseparable from the staff and requires the professional knowledge and quality of the staff to be taken seriously. Under the rapid economic development in China, the hardware facilities and software facilities of civil aviation are gradually being improved. There are still some deficiencies in staff management. Therefore, we should train professional knowledge of staff, improve the professional knowledge of managers and improve the overall quality of staff, so that staff members can handle well in crisis situations. Thereby enhancing the level of air traffic control in civil aviation and better promoting the development of civil aviation.

Nowadays, the economy is developing rapidly and the people-oriented thinking is also the demand of the times. In the air traffic control of civil aviation, it is more necessary to have people-centered thinking and people's life safety and the safety of the aircraft that the risk management of the civil aviation system focuses on. Therefore, in our people-oriented Thought plays a decisive role and can serve as the goal of China's civil aviation sustainable development.

\section{Conclusion}

To sum up, China's civil aviation is an important part of air traffic. Therefore, it is necessary to attach importance to the development of civil aviation, enhance the level of air traffic control in civil aviation, raise and attach importance to it in various aspects, implement measures in a scientific and theoretical way, Traffic control measures for the scientific implementation of the actual work to play an active role in promoting the workforce to improve the professional standards and overall quality, so as to ensure the quality of civil aviation air traffic control, but also focus on people-oriented, civil aviation Traffic control is mainly to protect human security, so ah responsible for the safety of human life, attention to the nature of control. Although China has made great achievements in civil aviation, there are still many deficiencies. Therefore, it is necessary to learn and study advanced transportation control systems from the advanced countries, take its essence to its dregs, and improve its own methods of civil aviation traffic control. Good to promote the development of China's civil aviation and promote China's economic progress.

\section{References}

[1] Xu Zhilei. Research on Threats and Error Control in Air Traffic Control Operation [J]. Science and Technology Innovation and Application. 2017 (18)

[2] Chen Yue. Causes of air traffic control errors in civil aviation and risk management [J]. Science and Technology. 2017 (15)

[3] Chen Zhiqian, Guo Xin, Yan Hongyu. Reflections on the construction of air traffic control standardization system [J]. China standardization. 2017 (15)

[4] Bai Zhenxing. Impact of complex weather on air traffic control command [J]. Science and Technology Innovation Herald. 2017 (16)

[5] Xian Jing. Air traffic control safety management system and its information system [J]. Science 
and Technology Innovation Review. 2017 (16)

[6] Dong Zemeng. On the quality of air traffic control operation based on BP network [J]. Communications World. 2017 (17)

[7] Ma Yubin. How to effectively prevent air traffic control risk [J]. Fujian Quality Management. $2016(02)$ 